\title{
527-THE ELECTROOXIDATION OF GLUCOSE ON PLATINUM ELECTRODES IN BUFFERED MEDIA
}

\author{
M.F.L. de MELE, H.A. VIDELA and A.J. ARVÍA
}

Instituto de Investigaciones Fisicoquimicas Teóricas y Aplicadas (INIFTA), Casilla de Correo 16, Sucursal 4, 1900 La Plata (Argentina)

(Revised manuscript received December 13th 1982)

\section{SUMMARY}

Kinetic studies of glucose electrooxidation are of special interest in fundamental and applied electrochemistry. The electrochemical reaction on bright $\mathrm{Pt}$ electrodes is investigated through the application of combined potential/time perturbation programs and electrolytes of different compositions at temperatures ranging from 30 to $64^{\circ} \mathrm{C}$. The electrooxidation of glucose should occur through the formation of several intermediate species and the overall reaction pathway should consist of different stages considering electroadsorption, chemical and electrochemical processes. The influence of potential perturbation conditions, anion adsorption, inhibition reactions of products and temperature are analysed through changes in $U / I$ profiles.

\section{INTRODUCTION}

The electrooxidation of glucose on platinum has been studied by several authors in relation to the development of biofuel cells as implantable power sources for cardiac pacemakers [1,2] and more recently in connection with glucose sensors. In this case a quantitative relation between current and glucose concentration is proposed for monitoring glucose concentration levels in vivo [3-7]. The reaction was investigated using different perturbation techniques in buffered electrolytes at neutral $\mathrm{pH}$ or acid solutions either on smooth or platinized platinum electrodes [5-17]. The potentiodynamic $U / I$ profiles depend on the potential perturbation conditions, the electrode treatment, the electrolyte composition, the presence of possible reaction products and temperature, but little attention has been paid to their influence on the process.

The present paper refers to the electrooxidation of glucose on bright platinum electrodes using electrolytes of different compositions, including the influence of the reaction products at temperatures ranging between 30 and $64^{\circ} \mathrm{C}$. Special attention is paid to the influence of those variables on the electrooxidation of glucose through changes which are produced in the corresponding $U / I$ profiles.

At present it appears that the kinetic information available in the literature is still 
insufficient to postulate a general reaction pattern for the electrooxidation of glucose in Pt valid under the variable conditions found both in biological and non-biological systems.

\section{EXPERIMENTAL}

Experiments were carried out in a three-compartment Pyrex glass cell. A smooth Pt wire (polycrystalline, specpure, Johnson Matthey Chemicals) of $0.16 \mathrm{~cm}^{2}$ apparent area was used. The counterelectrode was also made of platinum. A properly shielded saturated calomel electrode was used as reference. The potentials in the following text and figures are referred to the saturated calomel electrode. Potentiodynamic techniques were employed in the potential range from -0.6 up to $+1.0 \mathrm{~V}$. The working electrode was perturbated with different potential/time programs, including triangular potential sweep (TPS) and linear potential sweep combined with different potential steps [15]. To provide a reproducible working electrode surface the electrode was first stepped at $1.2 \mathrm{~V}$ and then to either 0.8 or $1.0 \mathrm{~V}$, to remove any trace of adsorbed organic species from the surface and to form a passive, oxygencontaining film on the electrode. Later, the potential was set at the electroadsorption potential $\left(U_{a d}\right)$ for a certain time $\left(t_{a d}\right)$ and subsequently, a triangular sweep was applied towards the positive potential direction from $U_{a d}$ up to either 0.8 or $0.9 \mathrm{~V}$ and backwards to $U_{a d}$ to ensure the complete electroreduction of the oxygen-containing film produced during the anodic sweep.

The electrolyte compositions are given in Table 1 , where $c$ stands for the molar concentration of the reactant (glucose, arabinose), $I$ is the ionic strength and $\beta$ is the buffer capacity of the electrolyte mixture. The buffer capacity used in this work must be interpreted as the number of millimoles of strong alkali which has to be added to $1000 \mathrm{~cm}^{3}$ of buffer solution (without change in volume) to raise the $\mathrm{pH}$ from 0.1 unit below the stated value to 0.1 unit above it. The $\beta$ values shown in Table 1 were obtained from the literature [18]. Buffered solutions were obtained from dilution to

TABLE 1

Electrolyte solution used (see text)

\begin{tabular}{lcccllllll}
\hline $\begin{array}{l}\text { Solution } \\
\text { number }\end{array}$ & $c(M)$ & $A\left(\mathrm{~cm}^{3}\right)$ & $B\left(\mathrm{~cm}^{3}\right)$ & $\begin{array}{l}I(M) \\
\mathrm{K}_{2} \mathrm{HPO}_{4}-\mathrm{KH}_{2} \mathrm{PO}_{4}\end{array}$ & $\beta$ & $\mathrm{pH}$ & $\begin{array}{l}I(m) \\
\mathrm{K}_{2} \mathrm{SO}_{4}\end{array}$ & $\begin{array}{l}I(M) \\
\text { Total }\end{array}$ \\
\hline 1 & & & & & & & & & \\
2 & 0.03 & 29.2 & 124.0 & 0.20 & 1.8 & 7.4 & 0.80 & 1.00 \\
3 & 0.03 & 74.2 & 8.6 & 0.05 & - & 7.1 & 0.30 & 0.43 \\
4 & 0.10 & 66.6 & 66.6 & 0.13 & - & 7.0 & 0.30 & 0.56 \\
5 & 0.10 & 133.3 & 133.3 & 0.26 & - & 7.0 & 0.30 & 0.70 \\
6 & 0.10 & 200.0 & 200.0 & 0.40 & - & 2.6 & 0.30 & 0.30 \\
7 & 0.10 & 0 & 0 & 0 & - & 7.0 & 0 & 0.40 \\
8 & 0.10 & 200.0 & 200.0 & 0.40 & 2.8 & 7.1 & 0 & 0.04 \\
\hline
\end{tabular}


$1000 \mathrm{~cm}^{3}$ of different mixtures of $A \mathrm{~cm}^{3}$ of $0.5 M \mathrm{KH}_{2} \mathrm{PO}_{4}+B \mathrm{~cm}^{3}$ of $0.5 \mathrm{M}$ $\mathrm{K}_{2} \mathrm{HPO}_{4}$. To increase the total ionic strength $\mathrm{K}_{2} \mathrm{SO}_{4}$ was added. Solution 6 was prepared by dilution of $0.1 \mathrm{M} \mathrm{H}_{2} \mathrm{SO}_{4}$ to $\mathrm{pH} 2.6$ and by adding $\mathrm{K}_{2} \mathrm{SO}_{4}$ to $0.3 \mathrm{M}$ total ionic strength. Solutions were prepared from triply distilled water and A.R. chemicals. Runs were made at $30^{\circ} \mathrm{C}$. Occasionally experiments in the $30-64^{\circ} \mathrm{C}$ temperature range were also made.

\section{RESULTS}

The voltammetric response of bright Pt electrodes in the electrolyte in the absence of glucose (Fig. 1) shows the electroadsorption and the electrodesorption of hydrogen atoms in the -0.6 to $-0.2 \mathrm{~V}$ potential range. The -0.2 to $0.0 \mathrm{~V}$ potential range corresponds to the double-layer charging and discharging region. During the positive-potential-going scan at potentials greater than $0.0 \mathrm{~V}$ the electroadsorption of oxygen takes place. The corresponding electrodesorption process is observed during the negative-potential-going scan at potentials within the 0.3 to $-0.1 \mathrm{~V}$ range. The voltamperogram corresponding to glucose electrooxidation on $\mathrm{Pt}$ (Fig. 1) shows three current peaks during the anodic scan. Peak $I$ is found in the potential range corresponding to the electrodesorption of adsorbed $\mathrm{H}$ atoms ( $\mathrm{H}$-adatoms) on $\mathrm{Pt}$. Peak II is at the end of the double-layer region and peak III is recorded in the potential range where the $\mathrm{Pt}$ surface is partially covered with a monolayer of oxygen-containing species. During the cathodic scan, peak $\mathrm{V}$ and hump IV occur after the partial electrodesorption of the oxygen-containing species covering the $\mathrm{Pt}$ surface.

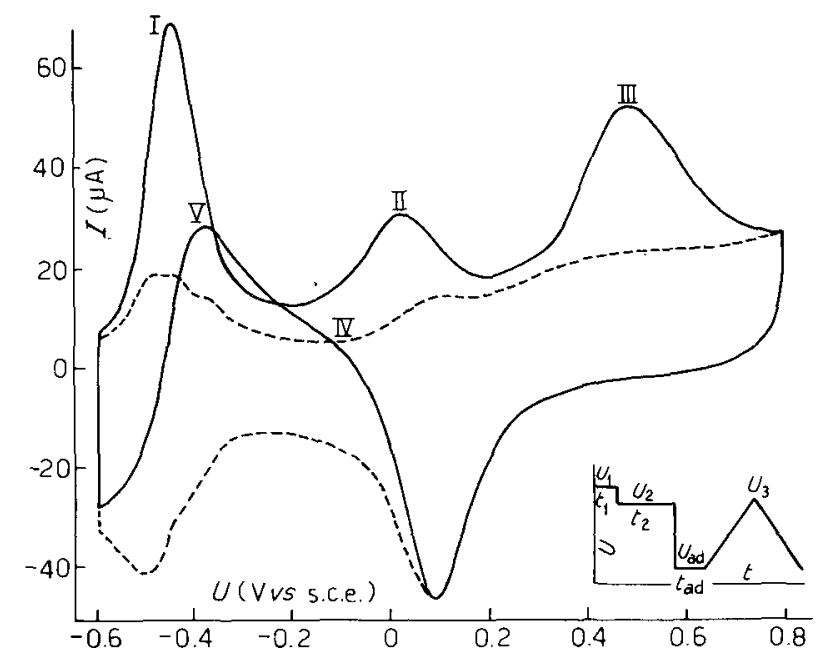

Fig. 1. Potentiodynamic $U / I$ profile run in solution 1 (glucose) at $T=37^{\circ} \mathrm{C}$. (- - - - -) Base electrolyte. Potential/time perturbation program (PP) is also shown. $U_{1}=1.2 \mathrm{~V}, t_{1}=10 \mathrm{~s} ; U_{2}=1.0 \mathrm{~V}, t_{2}=180 \mathrm{~s}$; $U_{a d}=-0.6 \mathrm{~V}, t_{a d}=10 \mathrm{~s}$. 
The potential versus current plots change by increasing the phosphate buffer concentration at constant $\mathrm{K}_{2} \mathrm{SO}_{4}$ concentration (Fig. 2). A remarkable decrease of peaks II and III as well as the change of the complex peak IV-V is observed when the phosphate concentration is increased (Fig. 2). In buffer solutions without $\mathrm{K}_{2} \mathrm{SO}_{4}$, a similar behaviour has recently been reported [17]. On the other hand, runs made at constant total ionic strength and different phosphate concentrations (solutions 1 and 2) exhibit a similar electrochemical response.

In acid media in the absence of phosphate (Fig. 3) the current hump IV turns into a current peak, while peak V is apparently suppressed. Conversely, peak III becomes considerably higher than the rest of the anodic peaks. Similar results are obtained with alkaline and neutral solutions.

Figure 4 shows repetitive potential sweeps recorded after applying a complex perturbation program, which consists in stepping the electrode at 1.2 and $1.0 \mathrm{~V}$, and to avoid electrode blockage by organic substances during the anodic sweep, a triangular potential sweep in the negative potential direction from a certain potential

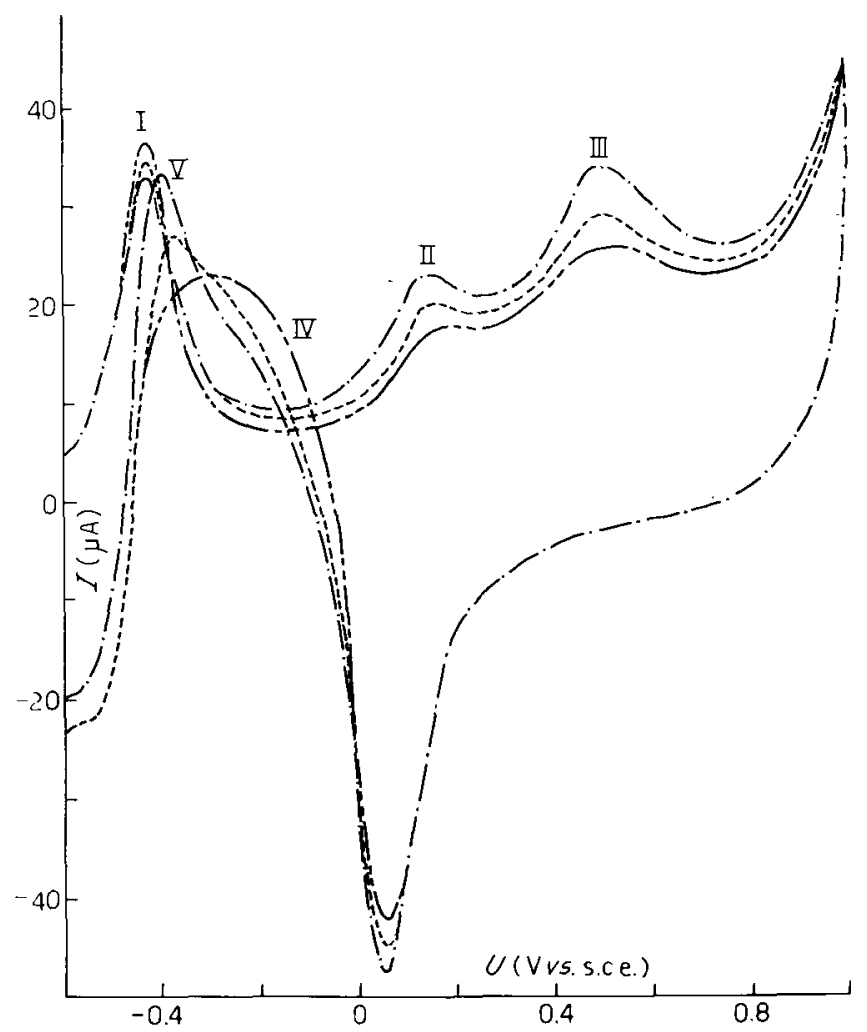

Fig. 2. $U / I$ profiles corresponding to repetitive TPS run at $T=30^{\circ} \mathrm{C}:(\cdot-\cdot)$ In solution $3 ;(-\cdot-\cdot)$ solution 4 ; ( - - -) solution 5 (glucose). 


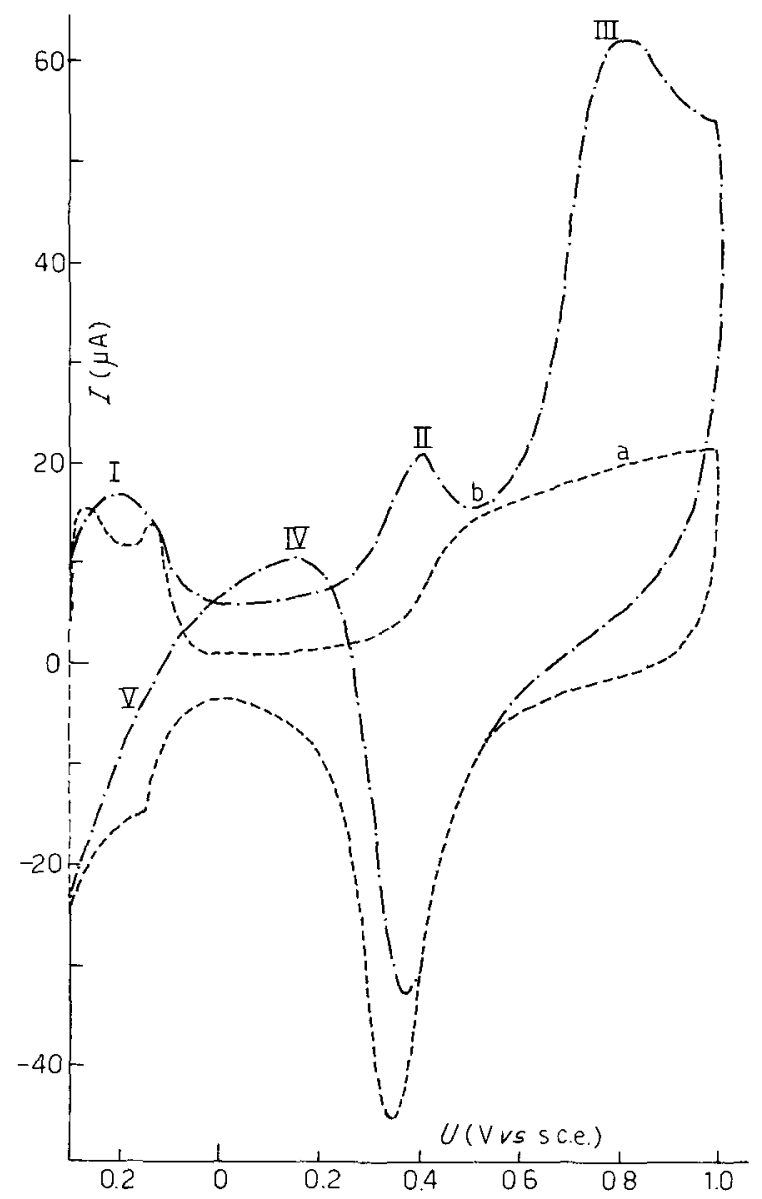

Fig. 3. $U / I$ profiles corresponding to repetitive TPS run at $T=30^{\circ} \mathrm{C}$ : (a) base electrolyte; (b) solution 6 (glucose).

$U_{3}$ to $-0.6 \mathrm{~V}$ is applied. The $U / I$ displays corresponding to the first and the second cycles are shown in Fig. 4. During the first sweep, large anodic currents are recorded, while during the second sweep a small current is recorded because of the severe inhibition of the processes (Fig. 4a). When $U_{3}$ is increased (Fig. 4b) the inhibition effect decreases.

The largest contribution of peak $I$ is obtained when $t_{a d}$ is small. A further increase of $t_{\text {ad }}$ produces a gradual inhibition of peak I. This inhibition can, in principle, be attributed to some products formed in the initial electrooxidation reaction. The effect is more noticeable as the temperature increases (Fig. 5). When the reactant is arabinose (hemiacetalic structure) a similar behaviour is observed (Fig. 6). The voltammograms look like those recorded with glucose. 


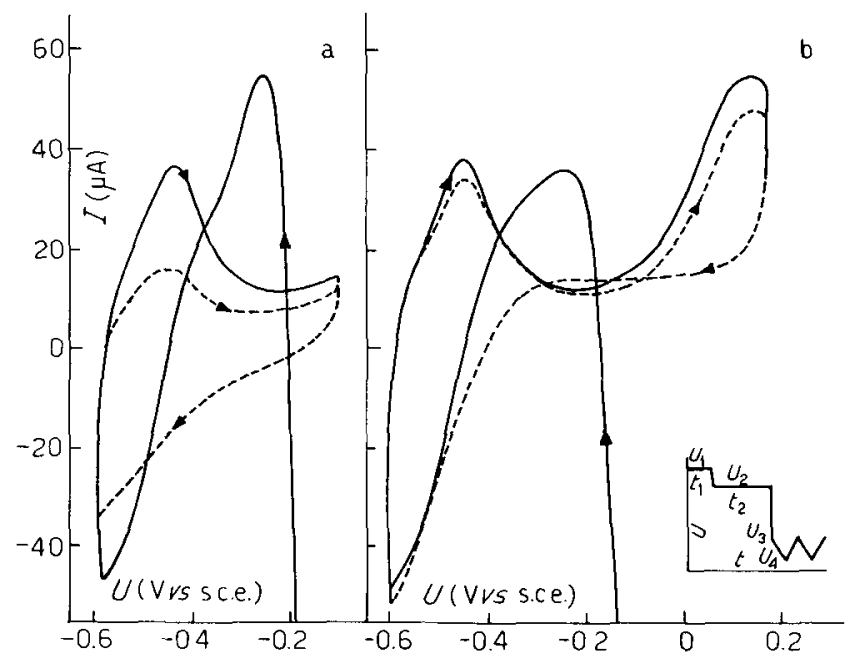

Fig. 4. Potentiodynamic $U / I$ profiles run at $30^{\circ} \mathrm{C}$ in solution 2 (glucose): ( - - ) first TPS; (- - . - -) second TPS. Potential/time perturbation program is also shown. $U_{1}=1.2 \mathrm{~V}, t_{1}=10 \mathrm{~s} ; U_{2}=1.0 \mathrm{~V}, t_{2}=180$ s. (a) $U_{3}=-0.1 \mathrm{~V}, U_{4}=-0.6 \mathrm{~V}$; (b) $U_{3}=+0.2 \mathrm{~V}, U_{4}=-0.6 \mathrm{~V}$.

The TPS potentiodynamic $U / I$ profiles, corresponding to buffer solutions saturated with a $\mathrm{CO}_{2} / \mathrm{N}_{2}$ mixture obtained after keeping the electrode at $-0.6 \mathrm{~V}$, show a strong inhibition of electrodesorption of hydrogen adatoms and a net increase of peak II as $t_{a d}$ increases (Fig. 7). This is probably related to the oxidation of $\mathrm{CO}_{2}$-reduced species formed in the hydrogen adatom potential region, which occurs in the potential region of peak II.

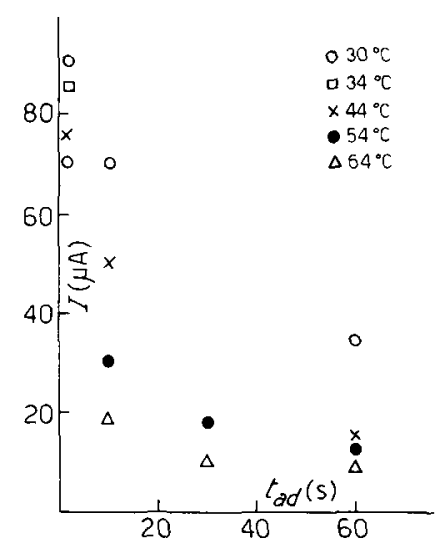

Fig. 5. Height of peak I versus adsorption time at different temperatures obtained with solution 7 (glucose, PP as in Fig. 1). 


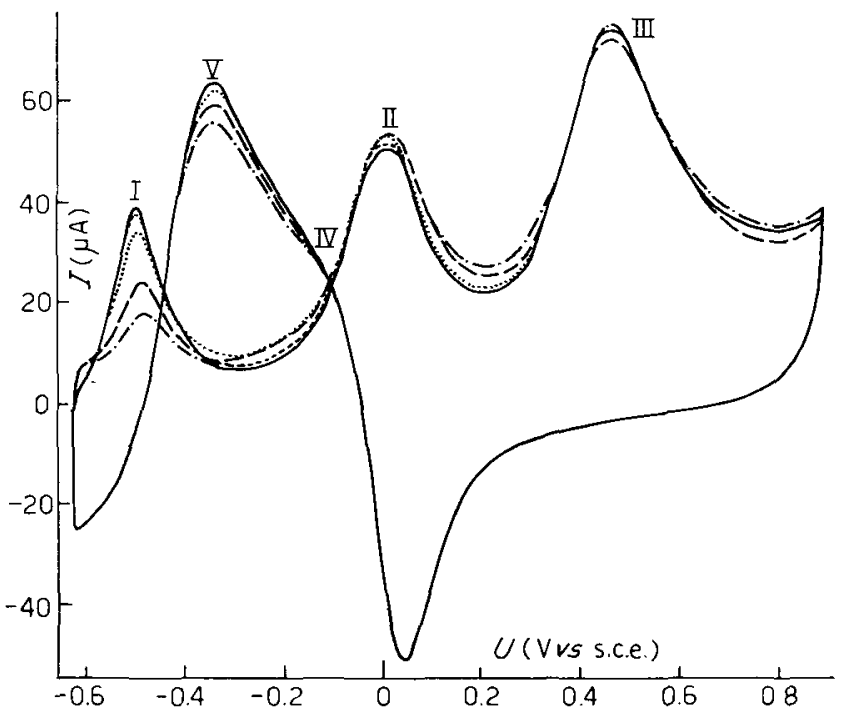

Fig. 6. Potentiodynamic $U / I$ profiles run in solution 1 (arabinose, PP as in Fig. $1, T=37^{\circ} \mathrm{C}$ ). $t_{a d}$ : $(\longrightarrow$

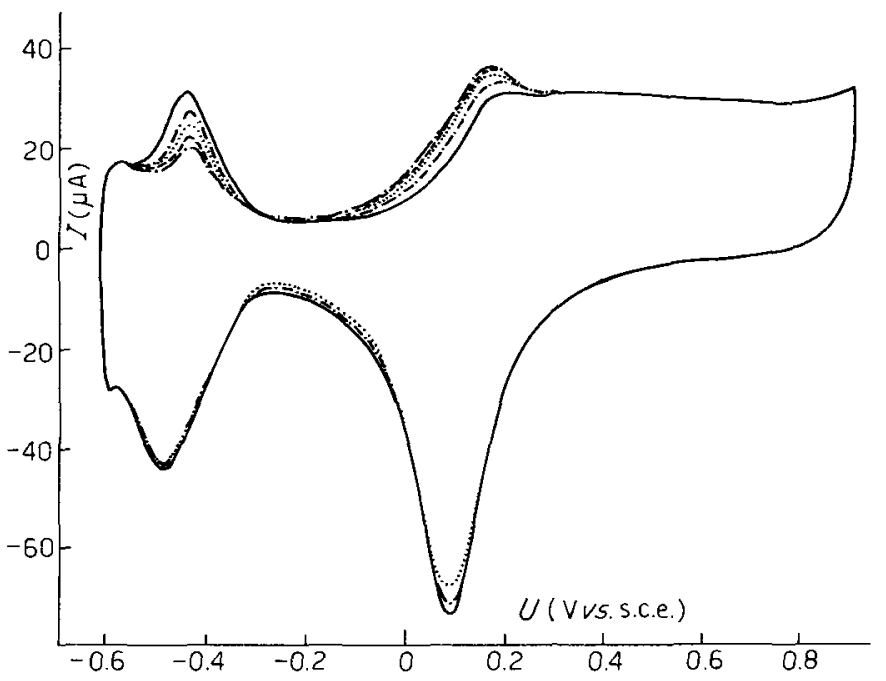

Fig. 7. Potentiodynamic $U / I$ profiles run with buffered electrolyte (solution 7 without organic substances) saturated with the gas mixture $\mathrm{N}_{2} 75 \%, \mathrm{CO}_{2} 25 \%$ (PP as Fig. 1). $t_{a d}:(-\longrightarrow) 10 \mathrm{~s} ;(\cdot-\cdot-\cdot) 20 \mathrm{~s}$; $(\cdots+) .30 \mathrm{~s} ;(\cdot-\cdot-) 40 \mathrm{~s} ;(\cdot-\cdot-\cdot) 50 \mathrm{~s}$. 


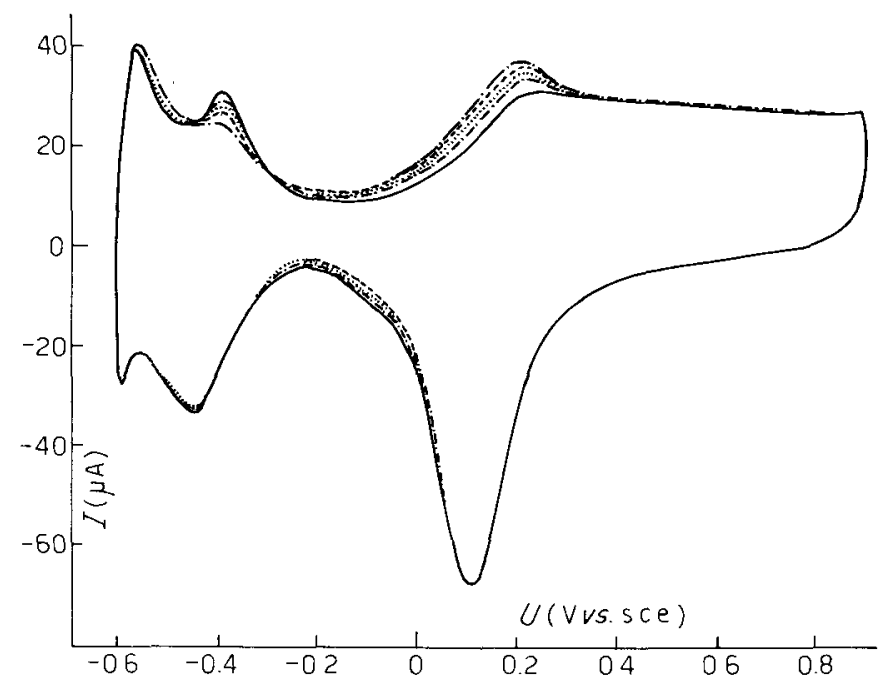

Fig. 8. Potentiodynamic $U / I$ profiles run with buffered electrolyte (solution 8 without organic substances) saturated with the gas mixture $\mathrm{N}_{2} 75 \%, \mathrm{CO}_{2} 25 \%$ (PP as Fig. 1). $t_{a d}:(-\longrightarrow) 10 \mathrm{~s} ;(\cdot-\cdot-\cdot) 20 \mathrm{~s}$; $(\cdots .) .30 \mathrm{~s} ;(-\ldots) .40 \mathrm{~s} ;(\cdot-\cdot-\cdot) 50 \mathrm{~s}$.

When low-concentration buffered solutions are used (Fig. 8) the $\mathrm{pH}$ decreases after $\mathrm{CO}_{2} / \mathrm{N}_{2}$ mixture saturation and the current in the hydrogen adatoms potential region increases.

\section{DISCUSSION}

Glucose exhibits various possible structures in equilibrium

$G(\alpha) \rightleftarrows G(\gamma) \rightleftarrows G(\beta)$

where the $\alpha$ and $\beta$ species, which are more abundantly present in aqueous solutions, correspond to the cyclic hemiacetalic forms and the species $\gamma$ denotes the free aldehyde form. The dehydrogenation of the closed ring forms ( $\alpha$ and $\beta$ ) yields glucono- $\delta$-lactone, which gives gluconic acid through a hydrolysis reaction. The open form $(\gamma)$ directly oxidizes to gluconic acid.

Through the determination of the rate of formation of intermediates it was concluded that the active form of glucose is the open chain [16]. However, the present results in agreement with data earlier reported $[12,13,15]$ show that only those species with a hemiacetalic structure behave similarly to glucose. The potentiodynamic electrooxidation of glucose, as well as the molecules involving a hemiacetalic group such as xylose and arabinose, imply, as a first stage, the electroadsorption of the molecule at a relatively low potential. The electroadsorption of glucose yielding different electroadsorbed species is related to the large anodic current recorded in the potential range of peak I (Figs. 1 and 5). The same occurs 
with the charge involved in potentiostatic transients recorded in the -0.6 to $-0.2 \mathrm{~V}$ potential region (Fig. 4a) [15], which are associated with the formation of adsorbed species according to an overall reaction such as

$\mathrm{G}+\mathrm{Pt} \rightleftarrows(\mathrm{Ri}) \mathrm{Pt}+x \mathrm{H}^{+}+x \mathrm{e}^{-}$

where $\mathrm{G}$ and $(\mathrm{Ri})$ denote glucose and adsorbed organic radical on the electrode respectively. According to Ernst et al. $[12,13]$, Ri could be ascribed to a chemisorbed form of the gluconolactone since lactone was the only direct reaction product detected at all potentials.

Chemical reactions between the adsorbed species and the H-adatoms simultaneously present on the $\mathrm{Pt}$ surface possibly occur. Such reactions account for the decrease of peak I when $t_{a d}$ increase at a constant $U_{a d}$ (Fig. 7). This effect is also observed when a hemiacetalic structure such as arabinose is used (Fig. 6). Similar decrease in current is observed when the repetitive triangular potential sweeps cover the hydrogen adatom potential range (Fig. 4).

The hemiacetalic group of the glucose molecule seems to play an important role in the electrooxidation process. Other monosaccharides and derivatives of dissimilar structures from that of glucose behave differently. In the case of the electrooxidation of carbohydrates and derivatives, a correlation between the rate of electrooxidation and the molecular structure can be derived $[15,19]$ in terms of the available reacting hydrogen atoms in the hemiacetalic group. This correlation resembles to some extent the electrochemical conversion order already established for the electrooxidation of other organic compounds $[20,21]$.

As the temperature or $t_{a d}$ increases, a decrease of the charge related to the electrodesorption of the $\mathrm{H}$-adatoms is observed. The decrease of peak I shows an inhibition by the adsorbed intermediates on the overall electrooxidation process (Fig. 5). In addition, the increase in the acidity with increasing temperature was reported [22] in relation to the decrease of the binding energy between proton and $\mathrm{C}$ atoms in the 1-position.

On the other hand, $\mathrm{CO}_{2}$ appears in solution as one of the possible reaction products of glucose electrooxidation [16]. Reduced ( $\mathrm{RiH})$ species is probably formed in the potential region corresponding to peak $\mathrm{I}$. The accumulation of $\mathrm{CO}_{2}$-reduced species when $t_{a d}$ increases, produces a decrease in the charge related to the electrodesorption of the $\mathrm{H}$-adatoms (Figs. 7 and 8 ). The degree of inhibition depends on the electrolyte composition.

A further complication, particularly in phosphate-containing solutions, arises from the effect of anion adsorption. The adsorbability of phosphoric acid ionic species on various metals, including $\mathrm{Pt}$, varies greatly with the solution $\mathrm{pH}$, with increasing temperature and with increasing electrochemical polarization [23]. The $\mathrm{HPO}_{4}^{2-}$ ions are probably adsorbed at the metal-electrolyte interface through the formation of an oxygen-metal adsorptive bond [24]. Therefore, taking into account the changes which are produced in $U / I$ profiles with different electrolytes, when the mechanism of the electrochemical oxidation of glucose at $\mathrm{Pt}$ is considered, a competitive adsorption between glucose and anions for the adsorption sites on the 
metal should be established. The desorption of $(\mathrm{Ri})$ or $(\mathrm{RiH})$ could probably be accelerated in the presence of phosphate anions. The latter, however, can also interfere with the formation of the ( $\mathrm{RiH}) \mathrm{Pt}$ species. In this way the activation of the electrooxidation reaction by phosphate ions in the hydrogen adatom potential range, when concentrated buffered solutions are used, can be explained.

The oxidation of the adsorbed intermediates is feasible at more positive potentials, as can be deduced through the partial activation of the electrode observed when the anodic limit of the potential sweep is fixed at potentials more positive than those corresponding to peak I (Fig. 4b). Therefore, the electrooxidation of glucose in the potential region of peak II occurs on a partially covered electrode, the main adsorbate probably being a chemisorbed form of lactone [12,13]. In this potential region, either glucono- $\delta$-lactone and gluconic acid $[12,13]$ or $\mathrm{CO}_{2}[16]$ are reaction products resulting from the electrooxidation of glucose. The $U / I$ relationship obtained for these compounds shows a current peak in the potential region of peak II of glucose voltamperogram (Figs. 7 and 8). Runs made with glucose solutions containing glucono- $\delta$-lactone, gluconic acid [8,9] and $\mathrm{CO}_{2}$ [14] show a strong inhibition for the electrooxidation of glucose.

The final product of any $(\mathrm{Ri})$ species is $\mathrm{CO}_{2}$, according to

$\mathrm{Pt}_{x}(\mathrm{Ri})+x \mathrm{H}_{2} \mathrm{O} \rightarrow \mathrm{CO}_{2}+n \mathrm{H}^{+}+n \mathrm{e}^{-}+x \mathrm{Pt}\left(\mathrm{H}_{2} \mathrm{O}\right)$

However, glucono- $\delta$-lactone, which yields gluconic acid through a hydrolysis reaction, is the main reaction product detected using spectrometric analysis $[12,13]$. Consequently, a general reaction mechanism must consider that the total number of electrons entering the overall reaction lies between 2 and 24 .

The overall reaction pathway should consist of different stages, considering the electroadsorption of glucose and chemical and electrooxidation processes occurring simultaneously in some potential regions.

The electroadsorption process should take into account the anion adsorption and the dehydrogenation processes, which may be accompanied by a bond breaking in the organic molecule and a desorption of adsorbed intermediates. In addition, the inhibition of further glucose adsorption and oxidation by some adsorbed reduced compounds cannot be disregarded. The electrooxidation of glucose should occur through the formation of a variety of intermediate species. The influence of anions in the oxygen electrosorption is already known and should influence the electrooxidation reaction.

Finally, under potentiodynamic conditions the contribution of each stage involved in the overall reaction pattern should also depend on the potential sweep rate and switching potentials.

\section{ACKNOWLEDGEMENT}

INIFTA is sponsored by the Consejo Nacional de Investigaciones Cientificas y Técnicas, the Universidad Nacional de La Plata and the Comisión de Investigaciones Científicas (Provincia de Buenos Aires). 


\section{REFERENCES}

1 E. Weidlich, G. Richter, F. von Sturm, J.R. Rao, A. Thorén and H. Lagergren, Biomater. Med. Devices Artif. Organs, 4 (1976) 277.

2 B.Y.C. Wan and A.C.C. Tseung, Med. Biol. Eng., 12 (1974) 14.

3 J.R. Rao, G.J. Richter, F. von Sturm and E. Weidlich, Bioelectrochem. Bioenerg., 3 (1976) 139.

4 C.C. Liu, L.B. Wingard, Jr., S.K. Wolfson, Jr., S.J. Yao, A.L. Drash and J.G. Shiller, Bioelectrochem. Bioenerg., 6 (1979) 19.

5 H. Lerner, J. Giner, J.S. Soeldner and C. Colton, J. Electrochem. Soc., 126 (1979) 43.

6 J. Giner, L. Marincic, J.S. Soeldner and C.K. Colton, J. Electrochem. Soc., 128 (1981) 2106.

7 J. Giner and J.S. Soeldner, Proceedings of a Workshop Conference, Freiburg, F.R.G., 1976, p.9.

8 E.M. Skou, 27th I.S.E. Meeting, Zürich, 1976, Extended Abstr. 279.

9 E.M. Skou, 29th I.S.E. Meeting, Budapest, 1978, Extended Abstr. 668.

10 E.M. Skou, Electrochim. Acta, 22 (1977) 313.

11 E.M. Skou and T. Jacobsen, 32nd I.S.E. Meeting, Dubrovnik/Cavtat, 1981, Extended Abstr. Vol. II, p. 800 .

12 S. Ernst, J. Heitbaum and C. Hamann, Ber. Bunsenges. Phys. Chem., 84 (1980) 50.

13 S. Ernst. J. Heitbaum and C. Hamann, J. Electroanal. Chem., 100 (1979) 173.

14 M.F.L. de Mele, H.A. Videla and A.J. Arvía, 32nd I.S.E. Meeting, Dubrovnik/Cavtat, 1981, Extended Abstr. Vol. II, p. 827.

15 M.F.L. de Mele, H.A. Videla and A.J. Arvía, Bioelectrochem. Bioenerg., 9 (1982) 469.

$16 \mathrm{~J}$. Giner and P. Malachesky, Proceedings of the Artificial Heart Program Conference, Washington D.C., 1969 , p. 839.

17 M.F.L. de Mele, H.A. Videla and A.J. Arvía, 6th Intern. Bioelectrochem. Bioenerg. Symp., Kibbutz Kiryat Anavim, Israel, 1981, p. 4.

18 C. Long, Biochemists' Handbook, E. and F.N. Spon, London, 1968, pp. 27-32.

19 M.F.L. de Mele, H.A. Videla and A.J. Arvia, J. Electrochem. Soc., 129 (1982) 2207.

20 S.N. Raicheva, S.V. Kalcheva, M.V. Christov and E.I. Sokolova, J. Electroanal. Chem., 55 (1974) 231.

21 E. Sokolova, Electrochim. Acta, 20 (1975) 323.

22 J.J. Christensen, J. Haward Rytting and R.M. Izatt, J. Chem. Soc. B, (1970) 1646.

23 M.N. Barikov, R.S. Vakhidov and W.V. Ioslovich, Elektrokhimiya, 16 (1980) 1012.

24 R.S. Vakhidov and M.N. Barikov, Elektrokhimiya, 11 (1975) 282. 